\title{
EL PISCO: PATRIMONIO DEL PERÚ
}

\section{PISCO: HERITAGE OF PERU}

Eduardo Dargent Chamot

Instituto del Vino y del Pisco de la Universidad de San Martín de Porres, Perú

\section{RESUMEN}

El presente trabajo hace un recorrido por la historia del aguardiente de vino peruano que hoy conocemos con el nombre de "pisco". Se explica su origen mencionando la noticia más antigua que se tiene de él y se hace hincapié en varios aspectos que han sido esgrimidos para pretender justificar el uso del nombre en otros lugares que tienen que ver con distribución temprana, aduciendo que en el Alto Perú "pisco" era una denominación genérica. Se alude a la etapa en la que el pisco llegó a su punto mínimo de producción explicando que no fue un abandono intencional sino guiado por las circunstancias. Finalmente se explica el proceso de generalización del nombre "pisco" para el aguardiente peruano.

Palabras clave: Aguardiente, alambique, cachaza, Corfú, falca, filoxera, majeños, Potosí, puntaya.

\begin{abstract}
This article takes the reader through the history of the wine brandy ${ }^{1}$ that is today known as "pisco". Explains its origin going back to the oldest reference known today. It pin-points the arguments that have been used to pretend that the name "pisco" was a generic name for the white brandy consumed in the Alto Peru region, today's Bolivia. Covers the periods of lowest production, explaining that it was not an intentional give up of the product but that it was caused by different circumstances. The last part explains the process of the generalization of the use of the name "pisco" to refer to the Peruvian wine brandy.
\end{abstract}

Key words: Brandy, alembic, still cachaza, Corfu, falca, phylloxera, majeños, Potosi, puntaya

1 En español la palabra brandy implica guarda en barricas pero en inglés el término es usado en general para los aguardientes. (In Spanish the term "brandy" is used only for destiled drinks that have not been kept in casks while in English it is used for all destiled alcohols). 


\section{Introducción}

El pisco es un aguardiente incoloro, destilado de vino, elaborado de acuerdo a reglas estrictas que incluyen características específicas: las ocho variedades de uvas autorizadas ${ }^{2}$; el rango de porcentaje de alcohol obtenido de forma natural en una destilación; la ausencia de agua, colorante, saborizante o cualquier otro aditivo; el frescor propio de no haber sido guardado en tonel; y su producción en los valles de Lima, Ica, Arequipa, Moquegua y Tacna, los que por sus características climáticas y de composición de suelos hacen de estos productos merecedores de la denominación de origen "pisco".

A diferencia del vino que acompaña a los seres humanos desde los orígenes de la civilización y es un proceso natural, el aguardiente es un invento relativamente reciente, fruto del ingenio humano y basado en los experimentos de los alquimistas del siglo XII. Las referencias tempranas a la destilación en Sudamérica son esquivas. La lectura de material brasileño llevaría a pensar que allá se destiló el jugo de caña y se produjo garapa - hoy cachaza- desde mediados del siglo XVI, mientras que el historiador Pablo Lacoste afirma que se ha encontrado en los archivos coloniales de Chile la referencia a un alambique fechado en 1586 y que habría sido fabricado en el corregimiento de Coquimbo. De confirmarse este dato con documentos originales, se trataría del alambique más antiguo registrado hasta hoy para la región ${ }^{3}$. En el caso del Perú no se han encontrado referencias a alambiques del siglo XVI, y en lo que concierne a destilados se mencionan sistemas más primitivos como las "pailas aguardienteras", citándose la de Zepeda en Quilloay o la de Pedro Manuel "El Griego" que se verán más adelante.

De acuerdo al historiador Lorenzo Huertas, las pailas aguardienteras son seguidas por las falcas, algunas de las cuales continúan siendo usadas. Los alambiques serían los terceros en la secuencia. Nada prueba o desaprueba que se hayan empleado los tres sistemas simultáneamente

Aunque no hay constancia de la fecha de su primera destilación en el Perú, se sabe que en los monasterios se producía "agua de rosas" sobre la base de pétalos de dicha flor y que servía para hacer medicinas y perfumes (Dargent, 2009). El proceso que aquí interesa, sin embargo, para producir aguardiente de uva, tiene como referente más antiguo el testamento de un griego de la isla jónica de Corfú, afincado en Ica. Pedro Manuel, llamado "El Griego" firmó su testamento en la villa de Valverde (Ica) el 30 de abril de 1613, consignando entre sus posesiones cantidades detalladas de aguardiente. En el documento, encontrado por Huertas en el Archivo General de la Nación, se describe también el equipo usado por el griego, el cual no cuenta con el serpentín propio del alambique sino que está provisto de "una caldera grande de cobre para sacar aguardiente con su tapa e cañón" de las pailas aguardienteras y de las falcas.

2 Las ocho variedades de uvas autorizadas son: Quebranta, Negra Criolla, Mollar, Uvina, Italia, Moscatel, Torontel y Albilla. Hasta hace poco las cuatro primeras eran llamadas "no aromáticas" y las cuatro últimas "aromáticas"; hoy se ha dejado de lado esa división porque se considera que todas son aromáticas aunque unas menos que otras. La variedad de pisco "Acholado" implica una mezcla de uvas pisqueras en el mosto. La Norma Técnica Peruana 211.001, 206. Bebidas alcohólicas. Pisco. Requisitos. 7 ma edición: especifica que debe ser la mezcla de vinos frescos o piscos de uvas pisqueras, término que se sigue usando.

http://diarioeldia.cl/articulo/economia/estudio-historiadores-valida-origen-comun-pisco-chileno-peru. 3.I.2014. 
En su testamento, Pedro Manuel además de pormenorizar propiedades, deudas y obligaciones, refiere que tiene "más treinta tinajas de burney y llenas de aguardiente que ternán ciento y sesenta botijuelas de aguardiente, más un varrill lleno de aguardiente que terná treinta votixuelas de dicha agua ardiente" (Huertas, 2013: 83; en testamento f. 470v).

Interesante para el tema aquí tratado es el hecho de que, además del aguardiente y de la falca, se incluyen dos referencias más relacionadas a la producción del vino y el aguardiente.

La primera, a continuación de la mención de la caldera, dice: "Dos puntayas la una con que pasa el caño y la otra sana que es más pequeña que la primera" (Ibíd.). La segunda está relacionada a envases. En ella reitera el nombre de uno y agrega otro: "Más siete tinajas de vurney y de sangley bacías" (Ibíd.).

Considerando que la madre de sus dos hijos era su esclava malaya a quien liberó y que al tiempo de redactar el testamento ya había fallecido, se supone que llegó al Perú del sureste asiático y que "vurney" haría referencia al sultanato de Brunei o al mismo Borneo. En cuanto al término "sangley", este es usado en Filipinas para referirse a los mestizos de chino y filipino, aunque originalmente era una palabra relacionada al comercio y a los comerciantes ${ }^{4}$. Por último, en Filipinas existe un lugar llamado Sangley Point. Se entendería entonces que con esos nombres se hace referencia a recipientes vinculados a esa parte del mundo.

"El Griego" no menciona su edad pero sí que al momento de redactar su testamento goza de buena salud, lo que hace pensar que probablemente vivió algunos años más. Por otro lado, detalla los nombres de los miembros de su familia. Sus padres "Manuel Bafia y Vela Cutzulena su mujer" (Ibíd.: 78; f. 464r.) ${ }^{5}$, ya fallecidos; Margarida Fava, su esclava y madre de sus hijos y el nombre de estos: "Marcos Manuel que será de edad de doze años poco más o menos y el otro (sic) se llama Pascuala Manuel que será de edad de ocho años antes más que menos" (Ibíd.: 85; f. 472r).

Si bien la fecha del testamento es 1613, está claro que Pedro Manuel venía produciendo vino y aguardiente de uva desde antes. Bastaría el comentario al final del documento en cuestión, donde declara que deja: "por mis bienes duzientas botijas de vino que están en mi casa y bodega de la cosecha del año pasado de seiscientos doze" (Ibíd.: 84; f. 471v). A esto se suman los últimos descubrimientos de Huertas sobre Pedro Manuel. Aunque en su testamento menciona que sus cuentas corren desde 1609 (Ibíd.: 81; f. 468r), ahora Huertas ha encontrado constancia de que estaba en Ica en 1608 y que en esa fecha tenía casa y alquilaba tierras para cultivar uvas ${ }^{6}$.

Otra referencia temprana a la elaboración de aguardiente peruano se encuentra en la descripción de Pedro de León Portocarrero, el llamado “Judío Portugués”. Esta relación fue escrita cuando ya León Portocarrero se hallaba de regreso en España. Los apuntes fueron tomados por lo tanto entre la fecha de su llegada al

4 “Sangley. Indio chino o japonés que pasa a comerciar a Filipinas". Diccionario de la Lengua Española. R.A.E. Decimonovena Edición, p. 741.

5 En el testamento claramente se indica "Bafia", pero el apellido griego es "Vafías", que significa pintor.

6 Información personal de Lorenzo Huertas en reunión de la Academia Peruana del Pisco. 
Perú en 1609 y la de su embarque a la península ibérica en 1616, lo cual lo hace prácticamente coetáneo del documento de "El Griego".

En las anotaciones que realizó a lo largo de los seis o siete años que pasó en el Perú, León Portocarrero menciona en varias oportunidades el vino y las uvas. Discute incluso los precios del vino explicando que lo elevado de estos se debe a que son llevados por mar. Al terminar su exposición al respecto brinda un dato importante para el tema que aquí interesa: “fazen mucho aguardiente en el Perú y muy bueno" (León, 2009: 41).

También es fundamental para conocer los orígenes del aguardiente peruano la información que brinda el padre Bernabé Cobo en su Historia del Nuevo Mundo. Cuenta el jesuita que en el Perú, hacia 1625, cuando vivía en Pisco, todos los productos de la vid eran aprovechados: "Todas las utilidades que resultan desta planta, a saber, de regalado fruto, de las pasas que se hacen muy buenas de la uva mollar, de arrope, aguardiente, vinagre y sobre todo de gran copia de vino" (Cobo, 1956).

Un dato temprano -aunque posterior a los citados arriba- es que incluye Lorenzo Huertas en su libro Cronología de la producción del vino y del pisco, cuando trata sobre la escritura pública fechada el 11 de diciembre de 1633, donde se menciona que el vecino de Ica y natural de Moguer, Alonso García de Zepeda, era dueño de una viña en Quilloay, de otras propiedades entre la que estaba una casa y unas tierras que "lindan con la acequia de Longar", además de "un lagar de madera y una paila de sacar aguardiente" (Huertas, 2012: 98).

Si bien la referencia descubierta por Huertas es la que marca la fecha más temprana conocida de la producción del pisco, las otras tres -la de Pedro de León Portocarrero, la del padre Cobo, ambas relativamente cercanas en el tiempo, y la de la viña de Alonso García de Zepeda en Quilloay, menos de una década después- confirman que la producción de pisco en el país no era un asunto aislado sino que estaba difundida en el primer tercio del siglo XVII.

\section{Las rutas del vino y del aguardiente}

El transporte del vino y del aguardiente en el Perú colonial fue arduo. Para la costa norte del país, la ruta más recurrida era la marítima, tanto por la dureza de los desiertos como por las avenidas. Flores Galindo explica que la ruta del norte era difícil porque en verano las crecidas de los ríos destruían los caminos improvisados y los puentes. Comenta que en la costa sur se repetía esta situación por lo que "era preferible recurrir al mar para transportar de Pisco a Lima las botijas de aguardiente sorteando así los peligros del desierto" (Flores, 1991: 53).

La ruta de Arica tenía tres posibilidades. Una que iba al Cuzco a través de Arequipa, otra que se dirigía a Tarapacá por la costa y una tercera que subía directamente a Potosí. Aunque el flujo del vino y del aguardiente de pisco se movía mayormente hacia el norte tanto del Perú como de toda la costa del Pacífico hasta Acapulco, también se realizaba el transporte desde ese puerto hasta Arica, destino inicial del azogue necesario para el proceso de amalgama con que se extraía la plata en Potosí. Gran parte de la provisión de vino y aguardiente para la sierra sur, y en especial para la región minera cuya cabeza y polo de atracción era la Villa Rica de Potosí, se realizaba desde los valles aguardenteros del sur del Perú. 
El trajín de vinos, aguardientes, pasas e higos secos que se iniciaba en los valles sureños de la costa peruana hasta el Cuzco y las Charcas se conoció inicialmente como la "Ruta de los Viñateros" y posteriormente se le cambió el nombre a "Ruta de los Majeños", en referencia directa al valle de Majes en Arequipa. El camino, saliendo de este valle, tomaba dos derroteros: uno que se dirigía al Cuzco y el otro a Paucartambo (Flores, Kuon, Samanez \& Amado, 2011: 194).

La ruta subía desde Majes hacia Cailloma y de allí seguían los trajinantes hasta la ciudad del Cuzco. En Langui y Layo la "Ruta de los Viñateros" empalmaba con el Camino Real que continuaba por el altiplano hasta la villa imperial de Potosí. En el año 2007, los autores de la obra Cuzco: desde la nieve de la puna al verdor de la amazonía pudieron recoger el testimonio de un anciano de Quijabamba en la "Ruta de los Majeños" que aún recordaba la llegada de los trajinantes del vino a su pueblo. Comentaba este testigo que: "Los majeños que llegaban a Quiquijana, se establecían aquí en la plaza y su llegada era un acontecimiento, porque traían vino y se emborrachaban y bailaban en esta plaza de Quiquijana. De aquí continuaban hacia Ocongate y Paucartambo a intercambiar productos (Flores et al., 2011: 195).

\section{La caída de la producción}

Hubo dos momentos en los que la producción del vino y del pisco decayó, pero hay que aclarar que no se trató de un abandono descuidado e intencional sino el resultado de una situación marcada por circunstancias muy especiales.

La primera ocurrió en torno a los años comprendidos en el proceso de la independencia y en el caos político que siguió. La segunda -la más mencionada por los internacionalistas- fue el reemplazo de los viñedos por cultivos de algodón, a raíz del alza del precio de este producto como consecuencia de la guerra civil norteamericana (1861-1865), y que se profundizó debido al azote de la filoxera, que destruyó los cultivos de vid en muchos valles de la costa ${ }^{7}$.

Sobre este descenso en la producción de vino y aguardiente en tiempos de la independencia y años siguientes, Carlos Buller sintetiza en pocas páginas el impacto de los cambios que se produjeron en el Perú y su repercusión en los viñedos y la industria anexa.

La revisión de los ciclos de producción que hace Buller en la región de Arequipa sirve para entender lo que ocurrió en todo el país. Esta mirada termina con la caída final y prácticamente la desaparición de la producción vinera en el sur peruano. El decaimiento, explica Buller, se inicia en la segunda década del siglo XIX. La tendencia de crecimiento "alcanza su cenit en 1816" y "a partir de entonces se inicia el reflujo". No será esta vez algo temporal. Insiste el autor mencionado en mirar con atención una cifra que espanta y que lo dice todo: "La producción conjunta de los tres valles de Arequipa cayó de 1’471,000 arrobas en 1816 a 350,000 en 1853, lo que representa una contracción general de 76\% en poco menos de cuarenta años" (Buller, 2011: 167).

7 El nombre científico de la Filoxera es: Dactylosphaera vitifoliae. Anteriormente se le llamaba Phylloxera vastratix, nombre que aún se encuentra en algunas publicaciones. 
Según este autor, las causas de la baja de producción fueron: ante todo el inicio de las guerras de independencia y su impacto múltiple, la escasez de mano de obra por las levas, la ruptura de los circuitos comerciales y la destrucción de la planta industrial. Agrega Buller que, a diferencia de lo ocurrido en crisis anteriores, en esta oportunidad confluyeron otras circunstancias que no permitieron la recuperación. A la guerra de independencia se sumó, a continuación, la guerra caudillista y la guerra de la Confederación Perúboliviana, que incluyendo prolegómenos y colas duró hasta entrada la década de 1840.

Pocos años antes de la independencia, en 1815, cuando ya se habían producido los levantamientos de Zela y Pallardelle en Tacna, el francés Julian Mellet visitó el Perú y recorrió varias ciudades de la costa. Mellet hizo interesantísimas observaciones en su viaje, las que publicó en París en 1824 con el nombre de Voyages dans l'intérieur de la Amérique Méridionale. En esta obra llena de aventuras dedicó unas líneas al puerto de Pisco y al tema que aquí se trata:

Pisco es un portezuelo de mar a 50 leguas sureste de la capital que mantiene gran comercio con Lima y Guayaquil, de vinos y aguardientes. Siempre hay gran número de embarcaciones que vienen a cargar estos dos artículos.

Los alrededores de la ciudad, a un cuarto de legua del mar, están cubiertos de viñas y producen en abundancia toda clase de excelentes frutas de Europa y América; el vino que se fabrica se llama lancha, y es reconocido, tal vez, por el mejor de todo el Perú; y el aguardiente es tan bueno y mucho más fuerte que el de Cognac, tan renombrado en Francia (Mellet, 1971: 91).

Las referencias de Mellet contrastan, a la vez que confirman, los apuntes del cónsul británico Charles Milner Ricketts, escritos once años más tarde para explicar los efectos que la guerra tuvo en el comercio del puerto y que se detallarán más adelante.

Se debe entender que la guerra de la independencia tuvo un considerable impacto en los viñedos de la costa, y que el valle de Pisco fue de los primeros en sufrir las consecuencias. Con la llegada de Lord Cochrane al puerto y la oferta de libertad a quienes se incorporaran a las fuerzas libertadoras, los esclavos se unían al ejército dejando tanto los cultivos como las industrias con poca mano de obra. A esto se sumaban las levas hechas al paso de los libertadores, que reducían aún más la capacidad productiva de las haciendas, ya que a la pérdida de mano de obra se sumaba la confiscación de bestias de carga.

El cónsul británico Ricketts, a quien ya se ha hecho referencia, en carta a su ministro en Londres Sir George Cannin, en septiembre de 1826, resume en un párrafo la situación de los productos de la vid en el Perú: "El cultivo de la vid se reduce a Pisco y sus inmediaciones. La cantidad de aguardiente que anteriormente se producía era 70,000 toneles de 18 galones cada uno, y 15,000 toneles de vino, aparte de una pequeña cantidad cerca de Arequipa; pero por la escasez de peones ahora no se produce más de 16,000 toneles de aguardiente y muy poco o nada de vino" (Ricketts, 1975: 25). 
Si bien hay años de desarrollo entre mediados de siglo y la guerra con Chile, en 1854, con el inicio del boom guanero, el gobierno del mariscal Castilla dio dos leyes de suma importancia para el Perú: la libertad de los esclavos y el final del tributo indígena. La visión liberal del momento entendía estos dos saltos a la modernidad del país más como una ventaja económica que social: tanto los ex esclavos que en adelante recibirían una paga por su trabajo, como los campesinos que dispondrían de un extra para sus gastos, acelerarían el comercio y el crecimiento de la economía nacional. La realidad fue que los ex esclavos, en su mayoría ancianos, se alejaron de las tierras de cultivo, mientras que los campesinos, al no tener que conseguir dinero para el injusto tributo, prefirieron sus propias chacras. El resultado fue el despoblamiento de las tierras agrícolas, la caída de la producción y la inmediata elevación en los precios de los alimentos.

De otro lado, la temida Filoxera Vastatrix, plaga de origen americano que destruyó los sembríos de vid en Europa, llegó al Perú a fines del siglo XIX en algunos plantones importados de Francia. En 1888 se la detectó en Moquegua, en 1896 en Chincha, y en las primeras décadas del siglo XX se fue esparciendo por Ilabaya, Cinto, Locumba, Vítor, Majes y demás. Donde se pudo, los agricultores sustituyeron con cultivos de algodón los campos de vid destrozados por dicha plaga, pues su longitud de hebra lo hacía destacar en el mercado. Así pudieron salvar sus campos y la fuente de trabajo de los campesinos.

\section{Los primeros registros del nombre "pisco"}

Es necesario aclarar desde cuándo se usa el término "pisco" como nombre genérico del aguardiente de vino peruano. En todo caso, para el producido en Ica la fecha no es más antigua que el inicio del siglo XIX, y para el destilado en la costa desde los departamentos de Lima a Tacna, con las características por todos conocidas, es mucho más tardía.

Es importante anotar que el aguardiente de vino que se enviaba al Alto Perú procedía tanto del puerto de Pisco como de los valles sureños, Arequipa y Moquegua en especial, y que a diferencia del que se embarcaba en Pisco - que podía ser denominado "Aguardiente de Pisco", siempre con la preposición "de"-, a los de los otros valles se les llamaba sencillamente aguardiente, si acaso agregando el valle de procedencia. Por lo tanto "pisco" e incluso "de Pisco" nunca fue una denominación genérica. En todas partes los destilados de vino eran conocidos como "aguardiente" y en todo caso, si había duda, se decía "aguardiente de uva" para diferenciarlo del más barato que era de caña.

$\mathrm{Si}$ bien se menciona reiteradamente el "aguardiente de Pisco", el término "pisco" para referirse específicamente al aguardiente de uva producido en la costa del Perú lo hallamos impreso recién en el siglo XIX.

Lorenzo Huertas describe el paso del uso específico del nombre al genérico aclarando que: "Al inicio, esta situación nominativa se produjo en la región iqueña. No todos los aguardientes tomaron la denominación de pisco, pero un buen número de personas, sobre todo de viajeros a quienes más les gustaba el apelativo pisco en lugar de aguardiente de uva, lo registraron así en sus cuadernos de notas" (Huertas, 2012: 125). 
Es especialmente interesante la anotación del viajero inglés William Bennet Stevenson, quien recorrió la costa peruana en 1814 y que al pasar por el puerto de Pisco, además de comentar la excelente calidad del destilado, los volúmenes de producción y los envases de arcilla cocida en los que se almacenaba, indica explícitamente: "el aguardiente generalmente llamado pisco, pues debe su nombre al lugar donde es hecho, es de buen sabor y sin color" (Stevenson, 1972: 169), con lo que deja el primer testimonio del nombre "pisco" como sinónimo y propio del destilado en cuestión.

Una década después, el clérigo británico Hugh Salvin visitó el país en los días cercanos a la batalla de Ayacucho, y en sus escritos menciona por su nombre al aguardiente de vino. En su diario de viaje anota que el 24 de abril de 1825 visitó el puerto de Pisco y comenta al respecto: "Este distrito es conocido por la fabricación de un licor fuerte que lleva el nombre de la ciudad" (Salvin, 1973: 52).

Hay otras dos menciones directas al aguardiente y al nombre "pisco". La primera la hace después de una visita al filósofo y científico franciscano fray Juan José Metralla en el convento de los Descalzos del barrio del Rímac. Luego de revisar los instrumentos de medición geográfica del fraile, este lo llevó a él y a sus acompañantes al refectorio donde estaba el superior del convento con otros monjes, comiendo fruta después de la cena. Señala Salvin: "El pis(c)o, fuerte licor destilado de uva, circulaba por la mesa y los monjes lo bebían puro" (Ibíd.: 15). La segunda referencia se ubica en Huaura, pequeña población de una sola calle al norte de Lima, famosa porque fue la primera del Perú donde se juró la independencia. Allí conoció a un franciscano quien -anota-, "nos ofreció excelentes quesos del país y pisco" (Ibíd.: 72). Ambas referencias del inglés son breves y sin mucha descripción, pero tienen la importancia de estar entre las primeras conocidas en las que se usa directamente el nombre "pisco" para referirse al aguardiente de vino peruano.

En 1828 Heinrich Witt utiliza el nombre "pisco" explícitamente para el aguardiente de uva producido en la región de Ica. El jueves 31 de julio del año mencionado el viajero alemán pasa por Chincha Baja y tras un recorrido de "8 leguas" llega a Pisco, población que describe de la siguiente manera: "Pisco es el puerto de Ica, del que se encuentra a 14 leguas de distancia, y desde aquí se exporta todo el brandy o aguardiente del país que se produce y destila en ese lugar. De ahí proviene el nombre de pisco, palabra con la que se conoce el brandy en todo el Perú" (Witt, 1992: 282).

En otro momento señala la diferencia entre "pisco" y los aguardientes del sur. Su comentario es muy claro y debe tenerse en cuenta: "La comercialización que la gente de Ica realiza del brandy llamado pisco, es bastante considerable; proveen de él a todos los departamentos del norte del Perú, mientras que el brandy o aguardiente producido en los valles de Majes, Vítor, Moquegua y otros, es consumido en el sur y exportado a Bolivia" (Ibíd.: 284).

Carlos Buller, investigador profundo del aguardiente en los valles del sur peruano, en una comunicación personal donde se trataba acerca de la antigüedad del nombre pisco, comenta:

En efecto, en el sur andino no se habla más que de "aguardiente" en las fuentes coloniales. Tazmías, cuadrantes decimales, protocolos notariales, guías de aduana, cajas reales y todo tipo de documentos 
oficiales, así como testimonios personales y referencias secundarias de la época sólo se refieren al aguardiente. Esto incluye, claro, a las aduanas de Potosí, que demuestran que este aguardiente llegaba de los valles de Moquegua y Locumba, principalmente, y algo de Vítor y Cinto, de ningún otro lado más. Ni siquiera se especifica "de uva" porque el de caña no circulaba (Comunicación del 15 de enero de 2014).

Aunque en los años siguientes se usaría con mayor frecuencia el nombre "pisco" para referirse al aguardiente iqueño, el término "aguardiente" en la publicidad de los destilados peruanos siguió siendo el más usado hasta entrado el siglo XX. Y el nombre se empleaba solo para referirse a los de Ica. Baste como muestra la carta que el 9 de junio de 1934 envió el señor Jorge Chamot Arróspide a la redacción del diario El Comercio, en la que comentaba una gestión hecha por él en Washington antes de esa fecha y que constituye una de las defensas tempranas de la peruanidad del pisco.

En su carta Chamot se refiere a un artículo aparecido en ese diario sobre los avances efectuados por el ingeniero Pedro Ricome para apoyar la exportación de los vinos y aguardientes peruanos, y a la sugerencia de que la embajada peruana en los Estados Unidos hiciese gestiones para impedir que se usara el apelativo "pisco" para aguardientes que no proviniesen del Perú.

Chamot aclara en su carta que durante la misión que desempeñó en Washington ante el Departamento de Estado norteamericano se ocupó justamente del tema del pisco y de su denominación de origen. En su carta traduce el texto de lo comunicado a las autoridades estadounidenses de esta manera: "Sobre este particular debe hacerse hincapié en que espíritus importados de otros países están usando el nombre 'pisco' que es producto exclusivamente peruano, ya que el único pisco genuino se produce en el área que rodea al puerto de Pisco en el Perú"8.

En tiempos más recientes si bien en Ica se le llamaba "pisco", el término genérico "aguardiente" continuó utilizándose en los valles al sur de este departamento ${ }^{9}$. Había una clara visión de que al aguardiente de uva se le llamaba por ese nombre y fue más adelante cuando el nombre de "pisco" se generalizó para referirse a los aguardientes de vino producidos en los valles que hoy tienen derecho a usarlo.

En efecto, es recién en 1946 cuando la Resolución Ministerial 1206 aclara de manera oficial lo que se llamará pisco. En ella se especifica que "llevará la denominación pisco seguida del nombre del lugar de origen, el producto obtenido exclusivamente de la destilación de los caldos provenientes de la fermentación de jugos de uva pura, preparados y destilados por los procedimientos conocidos" (Gutiérrez, 2011: 16).

8 Párrafo de la carta que Jorge Chamot, superintendente general de Aduanas, remitió al diario El Comercio, el 9 de junio de 1934 y que luego fue reproducida en la página 11 del número 55 de la Revista Vitivinícola y de Industrias Anexas, en junio del mismo año.

9 Recientemente en Moquegua el empresario pisquero y promotor turístico Víctor Paredes recordaba una situación ocurrida en 1952 entre el doctor Fernández Dávila, propietario de la Botica Francesa, y don Antonio Biondi Bernales, fundador de Piscos Biondi, natural de Ica, que tiene estrecha relación con el tema que aquí se desarrolla. En esa oportunidad Fernández Dávila hizo una invitación a tomarse un "aguardiente". Biondi socarronamente protestó diciendo: "Oye francés, eso se llama pisco". Ante eso el farmacéutico contraatacó de inmediato con un: "En tu tierra". 
Aún hubo de pasar casi medio siglo para que el 12 de diciembre de 1990 la Resolución Directoral № 072087, del Instituto de Investigación Industrial y de Normas Técnicas, más conocido por sus siglas ITINTEC, especificara que "pisco es una denominación de origen peruana para los productos obtenidos de la destilación de caldos, resultantes de la fermentación exclusiva de uva madura, elaborados en la costa de los departamentos de Lima, Ica, Arequipa, Moquegua y los valles de Locumba, Sama y Caplina del departamento de Tacna, de acuerdo a lo establecido en la Norma Técnica Peruana No 211-001 (Ibíd.: 17). Un mes más tarde, el 17 de enero de 1991, la mencionada resolución fue elevada a Decreto Supremo con el No 001-91-ICTI/IND (Ibíd.).

Actualmente el pisco está protegido por una Denominación de Origen, lo que implica que se refiere a un país, región o lugar determinado que sirve para designar a un producto elaborado dentro de su territorio. La Denominación de Origen Pisco está sujeta a un reglamento de fecha 14 de febrero de 2011 y administrada por un Consejo Regulador que se ocupa de garantizar su autenticidad y calidad, tanto en el ámbito interno como en el destinado a la exportación.

\section{Referencias}

Buller, C. (2011). Vinos, aguardiente y mercado. Auge y declive de la economía del vino en los valles de Arequipa (1770-1853). Lima: Quelca, Centro de Estudios Andinos.

Cobo, B. (1956). Historia del Nuevo Mundo. Biblioteca de Autores Españoles. Tomo II, Cap. XIII. Madrid.

Dargent, E. (2009). La cocina monacal en la Lima virreinal. Lima: Universidad de San Martín de Porres.

Flores, A. (1991). La ciudad sumergida. Lima: Editorial Horizonte.

Flores, J., Kuon, E., Amado, D. \& Samanez, R. (2011). Cuzco. Desde la nieve de la puna al verdor de la amazonía. Colección Arte y Tesoros del Perú. Lima: Banco de Crédito del Perú.

Gutiérrez, G. (2011). El desarrollo de la denominación de origen peruana pisco. Boletín de la Academia Peruana del Pisco, 2.

Huertas, L. (2012). Cronología de la producción del vino y el pisco. Perú 1548-2010. Lima: Editorial Universitaria de la Universidad Ricardo Palma.

Huertas, L. (2013). Testamento de Pedro Manuel y el inicio del pisco en el Perú. Homenaje en su IV Centenario 1613-2013. Perú 1548-2010. Lima: Editorial Universitaria de la Universidad Ricardo Palma.

León, P. (2009). Descripción del virreinato del Perú. Lima: Editorial Universitaria de la Universidad Ricardo Palma.

Mellet, J. (1971). Viajes por el interior de la América meridional. Impresiones sobre el Perú en 1815. En Relaciones de viajeros. Tomo XXVII, Vol. 1. Estudio preliminar y compilación de Estuardo Núñez. Colección Documental de la Independencia del Perú. Lima: Comisión Nacional del Sesquicentenario de la Independencia del Perú.

Norma Tecnica Peruana 211.001.2006. Bebidas alcohólicas. Pisco. Requisitos. 7ma Edición.

Ricketts, Ch. (1975). Informe al ministro George Cannin. Lima, 16 de septiembre de 1826. En Informes de los cónsules británicos. Heraclio Bonilla (Comp.). Lima: Instituto de Estudios Peruanos.

Salvin, H. (1973). Diario del Perú. En Relaciones de viajeros. Tomo XXVII, Vol. 4. Colección Documental de la Independencia del Perú. Lima: Comisión Nacional del Sesquicentenario de la Independencia del Perú.

Stevenson, W. B. (1972). Memorias sobre las campañas de San Martín y Cochrane en el Perú. En Relaciones de viajeros. Tomo XXVII, Vol. 3. Colección Documental de la Independencia del Perú. Lima: Comisión Nacional del Sesquicentenario de la Independencia del Perú.

Witt, H. (1992). Diario 1824-1890. Volumen I (1824-1842). Lima: Banco Mercantil. 
